\title{
Optimal Allocation and Sizing of Reactive Power Source for Voltage Profile Improvement on Nigerian 330kV, 24-Bus Grid System
}

\author{
${ }^{1}$ Olabode, O.E., ${ }^{2}$ Arowolo M.P, ${ }^{3}$ Olugbemi A.O \\ ${ }^{1}$ (Department of Electronic and Electrical Engineering, Ladoke Akintola University of Technology, PMB 4000, \\ Oyo State, Ogbomoso, Nigeria(Postgraduate Student)) \\ ${ }^{2}$ (Production Department, Hydro Power Plant, Mainstream Energy Solution Limited, Jebba North, Niger State) \\ ${ }^{3}$ (Department of Electrical and Electronics Engineering, Moshood Abiola Polytechnic, Abeokuta, Nigeria)
}

\begin{abstract}
Complete or partial blackout, poor power quality and damage to connected electrical pieces of equipment at the consumer end among others are day to day experience in Nigeria. One of the major causes of this scenario can be attributed to inability of electric power system to maintain a proper voltage level throughout the entire system. This paper addresses the problem of voltage violation on Nigerian 330kV, 24-bus grid system using shunt capacitor injection at defective buses. Newton-Raphson power flow solution method was use to carry out load flow analysis with and without shunt capacitor injection. The acceptable voltage limit ranges from 0.95 p.u to 1.05 p.u, voltage at bus $4,9,13,14,16$ and 19 were found to fall below the minimum acceptable limit of 0.95 p.u, to improve the voltage at these buses a calculated amount of Mvar was injected at

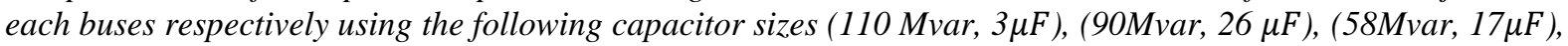
$(50 \mathrm{Mvar}, 16 \mu \mathrm{F}),(38 \mathrm{Mvar}, 12 \mu \mathrm{F})$ and $(20 \mathrm{Mvar}, 7 \mu \mathrm{F})$. The study shows that the injected MVAr via shunt-type capacitors significantly improve the system voltage profile, voltage angles andthe total system losses before compensation was found to be 82.5982MWand after compensation the losses reduced drastically to 82.2826MW.
\end{abstract}

Keywords: Load Flow Analysis, Newton-Raphson Iterative Method, Shunt Capacitor Compensation, Voltage Profile Improvement, Voltage Violation.

\section{Introduction}

One of the key operational challenges facing the electricitysupply utilities in most third world countries of the world including Nigeria is the problem of system voltage fluctuation on the power grid [1]. The quality of service supplied by power utilities to consumer loads such as residential loads, industrial loads and public service sector loads is undermined by fluctuation in system voltage from their nominal values throughout the entire power system. Attempt to keep the system voltage profile within the range of nominal values can be achieved either by controlling the production, absorption and flow of reactive power at all levels within the system $[2,3]$.

Generally, in power system, tap changing transformers and shunt capacitor injection are vital pieces of discrete controller for voltage profile and reactive power control and management [4]. The optimal candidate placement for the shunt capacitor injection is either at end of transmission line or at the load buses to appreciably increasethe power transfer capability of a transmission system without requiring new lines or larger conductors[5].

Compensating system voltage's profile improves active power of the network by raising its power factor and also decreases harmonic components due to large loads fluctuations from non-linear pieces of equipment [6]. This paper uses shunt capacitor injection for voltage profile improvement on Nigerian $330 \mathrm{kV}$, 24-bus transmission grid system because of its inherent advantages such as low initial cost, it has no moving part and its reaction to failures is quite adequate.

\section{Concept of voltage stability and shunt capacitor reactive compensation}

Power system ability to maintain a steady acceptable voltages at all buses during normal operating conditions and also after being subjected to a disturbance is termed voltage stability [7]. Power system voltage stability aimed at ensuring that voltages at the terminals of all equipment in the system are kept within the range of nominal values limits so as to avoid malfunction of and damage to the consumers' connected pieces of equipment.Keeping voltages close to these acceptable limits for which stabilizing controls are designed enhance system stability and as well guarantee maximal utilization of the transmission system [8].

Voltage instability on the other hand is the inability of power system to maintain acceptable voltages at all system buses under normal conditions and after being subjected to disturbances [9]. Causes of system voltage 
Optimal Allocation and Sizing of Reactive Power Source for Voltage Profile Improvement on ..

instability includes voltage drop due to active and reactive power flow through inductive reactance of the transmission network, reactive power demand beyond the sustainable capacity of the available reactive power resources as result of increase in system's disturbance, nature of transmission lines, problem of long transmission lines and poor power quality[11]. In general, its impact on the system has a wide spread as it depends on the relationship between real power $(\mathrm{P})$ transmitted, injected reactive power $(\mathrm{Q})$ and the voltage at the receiving end $\left(V_{R}\right)$. These relationships play a crucial role in power system stability analysis $[2,10]$.

Optimal allocation and sizing of reactive powersources is one of the core issues in grid systempower management aimed at keeping the system voltage profile at each load centers (buses) within acceptable limit, which will consequently bring a significant reduction in total system losses [12]. Reactive power sources for compensation could either be series or shunt type, since this paper uses the latter, the candidate placement for shunt-type capacitor could either be installed near the load, in a distribution substation, along the distribution feeder, or in a transmission substation but at the transmission substation both inductive and capacitive reactive compensation are installed [12,13].

The advantages of shunt capacitor reactive compensation on power system includes voltage regulation (control the voltage within required levels), system power losses reduction brought about by power factor improvement and lastly, it increases utilization of connected pieces of equipment at the consumer end.

\section{A. NEWTON RAPHSON LOAD FLOW METHOD}

\section{Problem formulation}

Load flow analysis enables us to determine the voltage magnitude and phase angle at each bus together with the real and reactive power flowing along the line. Solution methodologies available for solving load flow problem includeGauss-Seidel Method, Fast Decouple Newton-Raphson and Newton-Raphson method. NewtonRaphson method has superior advantages over others in term of convergence rate (quadratic convergence), less prone to divergence with ill-conditions and the number of iterations required is independent on the system's size.

In Newton-Raphson load flow method, the voltage magnitude is held constant at 1.0 per unit and the acceptable nominal values limits ranges from 0.95 per unit to 1.05 per unit. The candidate placements for reactive compensation are the weak points in the system with voltage magnitude less than 0.95 per unit.

\section{B. MATHEMATICAL MODELING OF NEWTON-RAPHSON LOAD FLOW METHOD}

The complex power flow equations for uncompensated transmission system solved by NewtonRaphson's iterative method are defined thus:

$$
\begin{gathered}
P_{i}-P d_{i}=\sum_{j=1}^{n}\left|V_{i} V_{j} Y_{i, j}\right| \cos \left(\theta_{i j}+\delta_{j}-\delta_{i}\right) i=1,2,3 \ldots, n \\
Q_{i}-Q d_{i}=-\sum_{j=1}^{n}\left|V_{i} V_{j} Y_{i, j}\right| \sin \left(\theta_{i j}+\delta_{j}-\delta_{i}\right) i=1,2,3 \ldots, n
\end{gathered}
$$

where $P_{i}=$ Real power generated at bus $i^{\text {th }}, Q_{i}=$ Reactive power generated at bus $i^{t h}, P d_{i}=$ Real power consumed at bus $i^{t h}, Q d_{i}=$ Reactive power consumed at bus $i^{\text {th }}, \mathrm{V}$ is the bus voltage, $\delta$ is the angle associated with $\mathrm{V}, Y_{i, j}$ is the element of bus admittance matrix, $\theta$ is the angle associated with $Y_{i, j}$.

The solution of equations (1) and (2) enables us to identify weak points in the system where the voltage magnitude are less than 0.95 per unit, these weak buses need reactive compensation, for compensated transmission system, equation (2) is modified and is defined by equation (3)

$$
Q_{i}-Q d_{i}+Q c_{i}=-\sum_{j}\left|V_{i}\right|\left|V_{j}\right| Y_{i, j} \sin \left(\theta_{i j}+\delta_{j}-\delta_{i}\right)
$$

$Q c_{i}=$ additional reactive power support at bus $i^{t h}$

\section{MATHEMATICAL MODELING OF SHUNT CAPACITOR RATING}

The power factor of the system was raised from 0.85 to 0.96 for compensation purpose, the value of $Q c$ (additional reactive power) to be injected at buses where voltage violation occurred is given by equation (4) below:

$Q c=\frac{P}{\text { Power Factor }(1)} \sin \left(\cos ^{-1}\left(P F_{1}\right)\right)-\frac{P}{\text { Power Factor }(2)} \sin \left(\cos ^{-1}\left(P F_{2}\right)\right)$

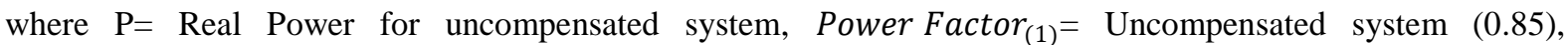
Power Factor $_{(2)}=$ Compensated system (0.96) 
The required capacitance value for compensation is given thus;

$C=\frac{Q c}{2 \Pi f V^{2}}$

\section{Results and discussion}

This section shows the result of power flow calculations simulated in MATLAB (R2013a) for 330kV Nigerian 24-bus system comprising of four thermal stations and three hydro stations.It was run on a portable computer with an Intel Core 2 Duo $(1.8 \mathrm{GHz})$ processor, 2GB RAM memory and MS Windows 7 as an operating system.

The accuracy of $1.000 e^{-003}$ was specified in the power flow program, the maximum power mismatch of $3.49553 e^{-07}$ was obtained and convergence occurred after the fifth iterations. Bus number 1 was taken as the reference bus since it has the highest generated power (MW) with voltage phase angle of zero degree. Figure 1 below shows the one-line diagram of the case study.

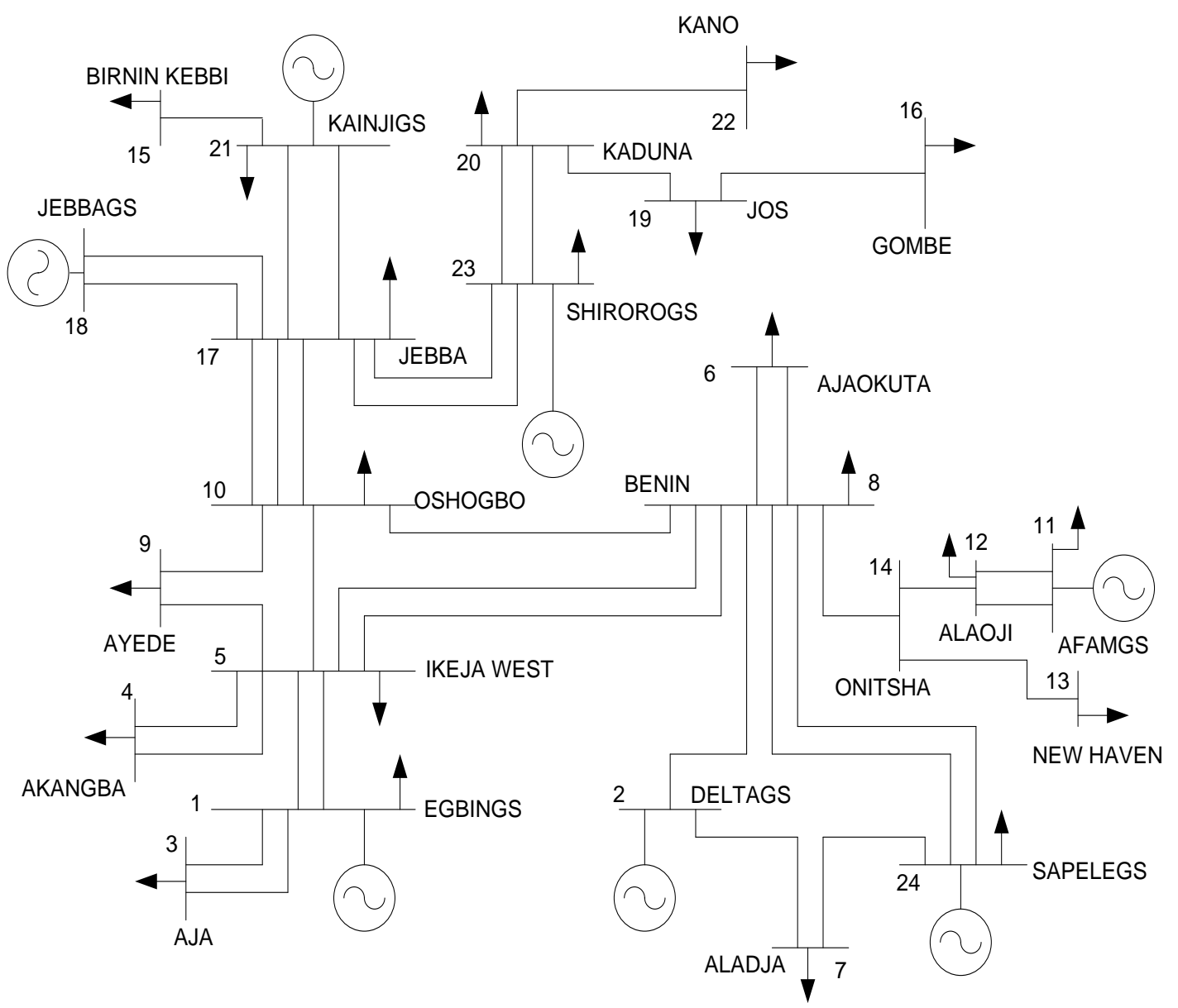

Figure 1: One-line diagram of Nigerian 330kV, 24-buses

(Source: National Control Centre, Power Holding Company of Nigeria, 2007) 
Optimal Allocation and Sizing of Reactive Power Source for Voltage Profile Improvement on ..

A. NEWTON-RAPHSON'S BASED POWER FLOW SOLUTIONS WITHOUT SHUNTCAPACITOR COMPENSATION

Table1: Power flow solution without shunt compensation

\begin{tabular}{|c|c|c|c|c|c|c|c|c|c|c|}
\hline \multirow{2}{*}{$\begin{array}{l}\text { Bus } \\
\text { No. }\end{array}$} & \multicolumn{2}{|l|}{ Voltage } & \multirow[t]{2}{*}{ Angle } & \multicolumn{2}{|c|}{ Load- } & \multirow[b]{2}{*}{ MW } & \multicolumn{3}{|c|}{-Generation-- } & \multirow[t]{2}{*}{ Injected } \\
\hline & Mag. & Degree & & Mvar & & & Mvar & & Avar & \\
\hline 1 & 1.050 & & 0.000 & 68.90 & 51.70 & 1483.40 & 769.0 & & .00 & \\
\hline 2 & 1.050 & & -1.066 & 0.00 & 0.00 & 670.00 & 3.01 & 0.00 & & \\
\hline 3 & 1.045 & & -0.284 & 274.40 & 205.80 & & 0.00 & 0.00 & 0.00 & \\
\hline 4 & 0.948 & & -5.609 & 344.70 & 258.50 & & 0.00 & 0.00 & 0.00 & \\
\hline 5 & 0.996 & & -5.159 & 633.20 & 474.90 & 0.00 & 0.00 & 0.00 & & \\
\hline 6 & 1.054 & & -6.916 & 13.80 & 10.30 & 0.00 & 0.00 & 0.00 & & \\
\hline 7 & 1.046 & & -2.635 & 96.50 & 72.40 & 0.00 & 0.00 & 0.00 & & \\
\hline 8 & 1.034 & & -6.556 & 383.30 & 287.50 & 0.00 & 0.00 & 0.00 & & \\
\hline 9 & 0.934 & & -7.689 & 275.80 & 206.80 & 0.00 & 0.00 & 0.00 & & \\
\hline 10 & 1.026 & & -4.785 & 201.20 & 150.90 & 0.00 & 0.00 & 0.00 & & \\
\hline 11 & 1.050 & & -17.192 & 52.50 & 39.40 & 431.00 & $464.8 B$ & 0.00 & & \\
\hline 12 & 1.033 & & -17.816 & 427.00 & 320.20 & 0.00 & 0.00 & 0.00 & & \\
\hline 13 & 0.929 & & -18.816 & 177.90 & 133.40 & 0.00 & 0.00 & 0.00 & & \\
\hline 14 & 0.791 & & -16.010 & 184.60 & 138.40 & 0.00 & 0.00 & 0.00 & & \\
\hline 15 & 1.010 & & -3.768 & 114.50 & 85.90 & 0.00 & 0.00 & 0.00 & & \\
\hline 16 & 0.875 & & -31.975 & 130.60 & 97.90 & 0.00 & 0.00 & 0.00 & & \\
\hline 17 & 1.050 & & -1.409 & 11.00 & 8.20 & 0.00 & 0.00 & 0.00 & & \\
\hline 18 & 1.050 & & -1.149 & 0.00 & $0.00 \quad 4$ & $195.00-5$ & -58.890. & .00 & & \\
\hline 19 & 0.945 & & -24.431 & 70.30 & 52.70 & 0.00 & $0.00 \quad 0$ & 0.00 & & \\
\hline 20 & 1.004 & & -17.167 & 193.00 & 144.70 & 0.00 & 0.000 & 0.00 & & \\
\hline 21 & 1.050 & & 1.752 & 7.00 & $5.20 \quad 62$ & $24.70-1$ & 114.670 & 0.00 & & \\
\hline 22 & 1.013 & & -15.453 & 199.801 & 149.90 & 0.00 & 0.00 & 0.00 & & \\
\hline 23 & 1.050 & & $-11.8 B 3$ & 320.10 & 256.10 & $38 B .90$ & 480.6 & 440.00 & & \\
\hline 24 & 1.050 & & -5.046 & 20.60 & 15.40 & 190.30 & 213.41 & 0.00 & & \\
\hline Total & 4200.70 & & 3166.20 & 4283.3 & $30 \quad 1757$ & 7.40 & .00 & & & \\
\hline
\end{tabular}

Voltage at bus $4,9,13,14,16$ and 19 were found to fall below the minimum acceptable limit of 0.95 p.u, to improve the voltage at these buses a calculated amount of Mvar was injected at each buses using the following capacitor sizes at bus 4 (110 Mvar, $3 \mu F)$, at bus 9 (90Mvar, $26 \mu F)$, at bus $13(58 \mathrm{Mvar}, 17 \mu F)$, at bus $14(50 \mathrm{Mvar}, 16 \mu F)$, at bus $16(38 \mathrm{Mvar}, 12 \mu F)$ and at bus $19(20 \mathrm{Mvar}, 7 \mu F)$. The result of power flow solutions with injection of shunt compensation is presented in Table 2 below. 
Optimal Allocation and Sizing of Reactive Power Source for Voltage Profile Improvement on ..

\section{B. NEWTON-RAPHSON'S BASED POWER FLOW SOLUTIONS WITH SHUNT- CAPACITOR COMPENSATION}

Table 2: Power flow solutions with shunt compensation

\begin{tabular}{|c|c|c|c|c|c|c|c|c|}
\hline \multirow{2}{*}{$\begin{array}{l}\text { Injected } \\
\text { No. }\end{array}$} & Bus & \multirow{2}{*}{$\begin{array}{l}\text { Voltage } \\
\text { Degree }\end{array}$} & \multirow{2}{*}{$\begin{array}{l}\text { Angle } \\
\text { MW }\end{array}$} & \multicolumn{2}{|r|}{-Load- } & \multicolumn{3}{|c|}{-Generation-- } \\
\hline & Mag. & & & Mvar & MW & Mvar & Mvar & \\
\hline 1 & 1.050 & 0.000 & & 68.90 & 51.70 & 1483.29 & 744.87 & 0.00 \\
\hline 2 & 1.050 & -1.063 & & 0.00 & 0.00 & 670.00 & -22.18 & 0.00 \\
\hline 3 & 1.045 & -0.284 & & 274.40 & 205.80 & 0.00 & 0.00 & 0.00 \\
\hline 4 & 0.989 & -5.609 & & 344.70 & 258.50 & 0.00 & 0.00 & 110.00 \\
\hline 5 & 0.996 & -5.158 & & 633.20 & 474.90 & 0.00 & 0.00 & 0.00 \\
\hline 6 & 1.054 & -6.914 & & 13.80 & 10.30 & 0.00 & 0.00 & 0.00 \\
\hline 7 & 1.046 & -2.633 & & 96.50 & 72.40 & 0.00 & 0.00 & 0.00 \\
\hline 8 & 1.034 & -6.553 & & 383.30 & 287.50 & 0.00 & 0.00 & 0.00 \\
\hline 9 & 0.975 & $-7.68 B$ & & 275.80 & 206.80 & 0.00 & 0.00 & 90.00 \\
\hline 10 & 1.026 & -4.784 & & 201.20 & 150.90 & 0.00 & 0.00 & 0.00 \\
\hline 11 & 1.050 & -17.177 & & 52.50 & 39.40 & 431.00 & 440.05 & 0.00 \\
\hline 12 & 1.034 & $-17.80 B$ & & 427.00 & 320.20 & 0.00 & 0.00 & 0.00 \\
\hline 13 & 0.999 & -18.806 & & 177.90 & 133.40 & 0.00 & 0.00 & 58.00 \\
\hline 14 & 0.972 & -16.004 & & 184.60 & 138.40 & 0.00 & 0.00 & 50.00 \\
\hline 15 & 1.010 & -3.766 & & 114.50 & 85.90 & 0.00 & 0.00 & 0.00 \\
\hline 16 & 0.975 & -31.974 & & 130.60 & 97.90 & 0.00 & 0.00 & 38.00 \\
\hline 17 & 1.050 & -1.408 & & 11.00 & 8.20 & 0.00 & 0.00 & 0.00 \\
\hline 18 & 1.050 & -1.148 & & 0.00 & 0.00 & 495.00 & -58.95 & 0.00 \\
\hline 19 & 0.955 & -24.430 & & 70.30 & 52.70 & 0.00 & 0.00 & 20.00 \\
\hline 20 & 1.004 & -17.166 & & 193.00 & 144.70 & 0.00 & 0.00 & 0.00 \\
\hline 21 & 1.050 & 1.753 & & 7.00 & 5.20 & 624.70 & -114.68 & 0.00 \\
\hline 22 & 1.013 & -15.452 & & 199.80 & 149.90 & 0.00 & 0.00 & 0.00 \\
\hline 23 & 1.050 & $-11.8 B 1$ & & 320.10 & 256.10 & 388.90 & 480.63 & 0.00 \\
\hline 24 & 1.050 & -5.044 & & 20.60 & 15.40 & 190.30 & 187.58 & 0.00 \\
\hline Total & & & & 4200.70 & 3166.20 & 4283.19 & 1657.34 & 366.00 \\
\hline
\end{tabular}

\section{RESULT SUMMARY}

The summary of the voltage improvement as well as reduction in total system loses caused by the injected Mvar is presented in Table 3 below:

Table 3: Shows the Summary of result obtained from the power flow Analysis

\begin{tabular}{|c|c|c|c|c|c|c|}
\hline $\begin{array}{l}\text { Bus } \\
\text { No }\end{array}$ & $\begin{array}{l}\text { Voltage Magnitude } \\
\text { with Shunt } \\
\text { Capacitor } \\
\text { Compensation }\end{array}$ & $\begin{array}{l}\text { Voltage Magnitude } \\
\text { without Shunt } \\
\text { Capacitor } \\
\text { Compensation }\end{array}$ & $\begin{array}{l}\text { Voltage Angle } \\
\text { with } \\
\text { Shunt Capacitor } \\
\text { Compensation }\end{array}$ & $\begin{array}{ll}\text { Voltage } & \text { Angle } \\
\text { without Shunt } \\
\text { Capacitor } \\
\text { Compensation } \\
\end{array}$ & $\begin{array}{l}\text { Total System Real } \\
\text { Power Losses with } \\
\text { Shunt Capacitor } \\
\text { Compensation }\end{array}$ & $\begin{array}{lr}\text { Total } & \text { System } \\
\text { Real } & \text { Power } \\
\text { Losses } & \\
\text { (without) }\end{array}$ \\
\hline 1 & 1.050 & 1.050 & 0.000 & 0.000 & \multirow[t]{11}{*}{82.2826} & \multirow[t]{11}{*}{82.5982} \\
\hline 2 & 1.050 & 1.050 & -1.063 & -1.066 & & \\
\hline 3 & 1.045 & 1.045 & -0.284 & -0.284 & & \\
\hline 4 & 0.989 & 0.948 & -5.609 & -5.609 & & \\
\hline 5 & 0.996 & 0.996 & -5.158 & -5.159 & & \\
\hline 6 & 1.054 & 1.054 & -6.914 & -6.916 & & \\
\hline 7 & 1.046 & 1.046 & -2.633 & -2.635 & & \\
\hline 8 & 1.034 & 1.034 & -6.553 & -6.556 & & \\
\hline 9 & 0.975 & 0.934 & -7.688 & $\begin{array}{l}-7.689 \\
\end{array}$ & & \\
\hline 10 & 1.026 & 1.026 & -4.784 & -4.785 & & \\
\hline 11 & 1.050 & 1.050 & -17.177 & -17.192 & & \\
\hline
\end{tabular}


Optimal Allocation and Sizing of Reactive Power Source for Voltage Profile Improvement on ..

\begin{tabular}{|l|l|l|l|l|l|}
\hline 12 & $\mathbf{1 . 0 3 4}$ & $\mathbf{1 . 0 3 3}$ & -17.808 & -17.816 \\
\hline 13 & $\mathbf{0 . 9 9 9}$ & $\mathbf{0 . 9 2 9}$ & -18.806 & -18.816 \\
\hline 14 & $\mathbf{0 . 9 7 2}$ & $\mathbf{0 . 7 9 1}$ & -16.004 & -16.010 \\
\hline 15 & 1.010 & 1.010 & -3.766 & -3.768 \\
\hline 16 & $\mathbf{0 . 9 7 5}$ & $\mathbf{0 . 8 7 5}$ & -31.974 & -31.975 \\
\hline 17 & 1.050 & 1.050 & -1.408 & -1.409 \\
\hline 18 & 1.050 & 1.050 & -1.148 & -1.149 \\
\hline 19 & $\mathbf{0 . 9 5 5}$ & $\mathbf{0 . 9 4 5}$ & -24.430 & -24.431 \\
\hline 20 & 1.004 & 1.004 & -17.166 & -17.167 \\
\hline 21 & 1.050 & 1.050 & 1.753 & 1.752 \\
\hline 22 & 1.013 & 1.013 & -15.452 & -15.453 \\
\hline 23 & 1.050 & 1.050 & -11.881 & -11.883 \\
\hline 24 & 1.050 & 1.050 & -5.044 & -5.046 \\
\hline
\end{tabular}

E. GRAPHICAL ILLUSTRATIONS

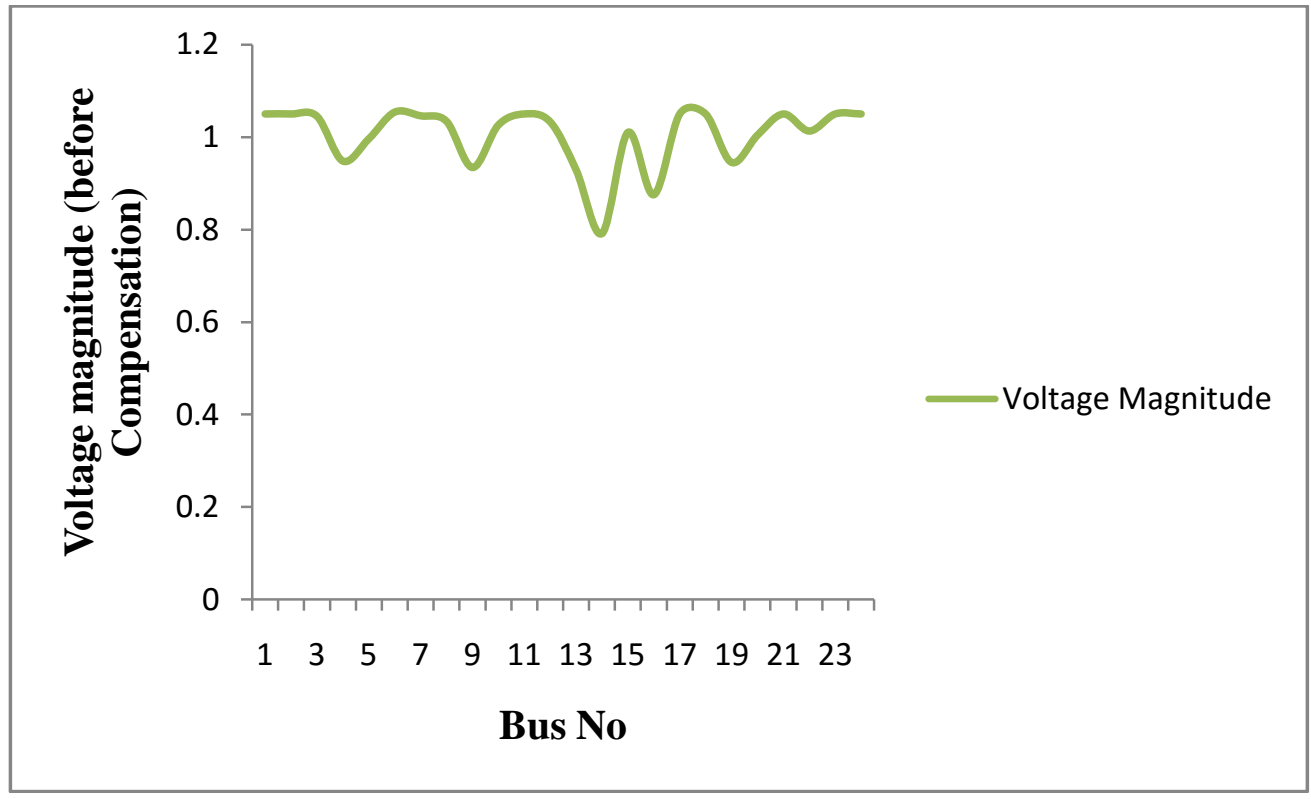

Figure 2: Bus No versus Voltage Magnitude (for shunt compensated System)

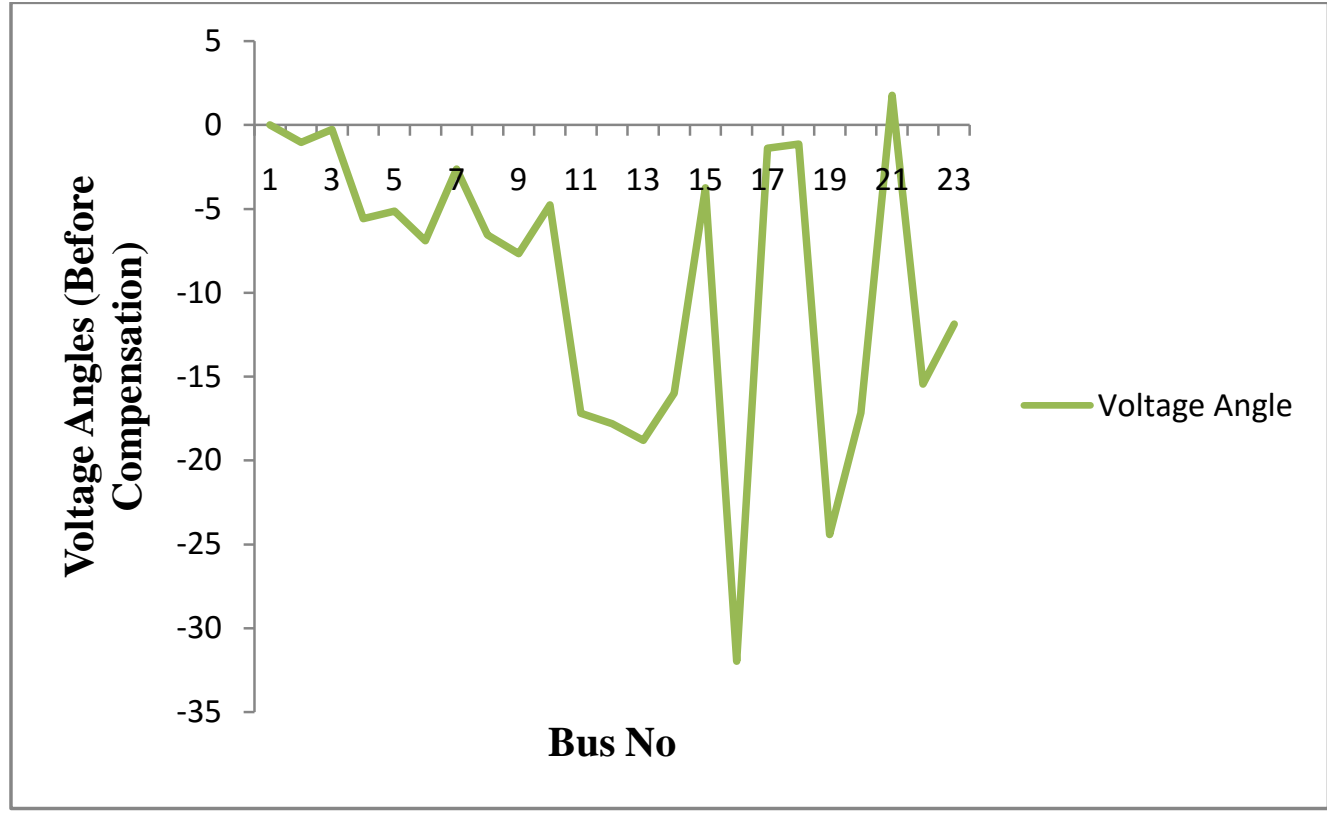

Figure 3: Voltage Angle (Uncompensated) versus Bus No 


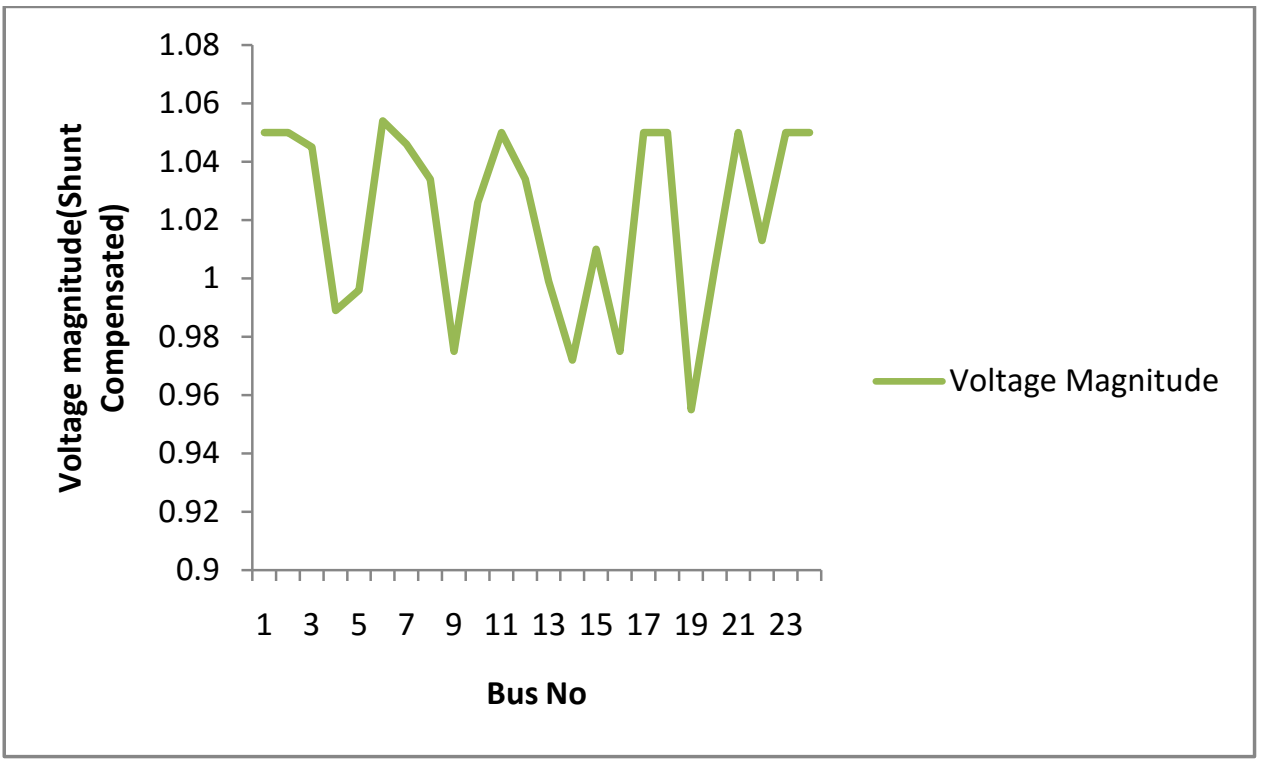

Figure 4: Voltage Magnitude (Compensated) versus Bus No

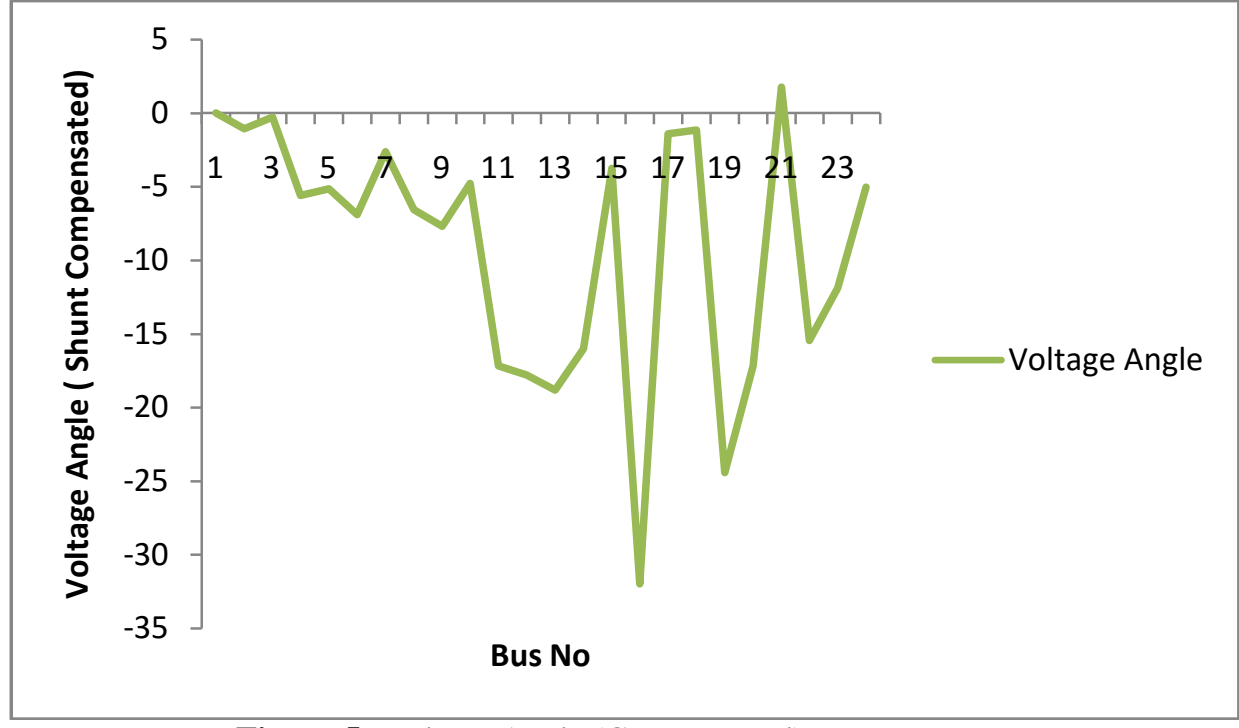

Figure 5: Voltage Angle (Compensated) versus Bus No

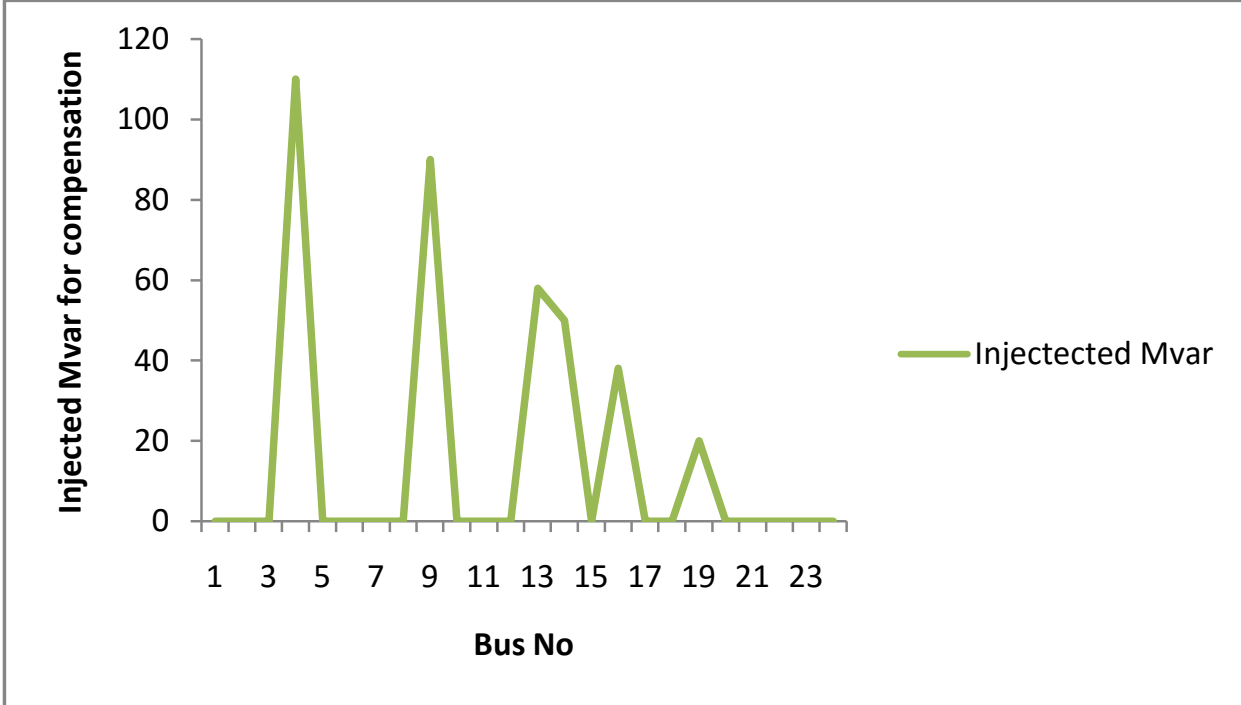

Figure 6: Injected Mvar versus Bus No 


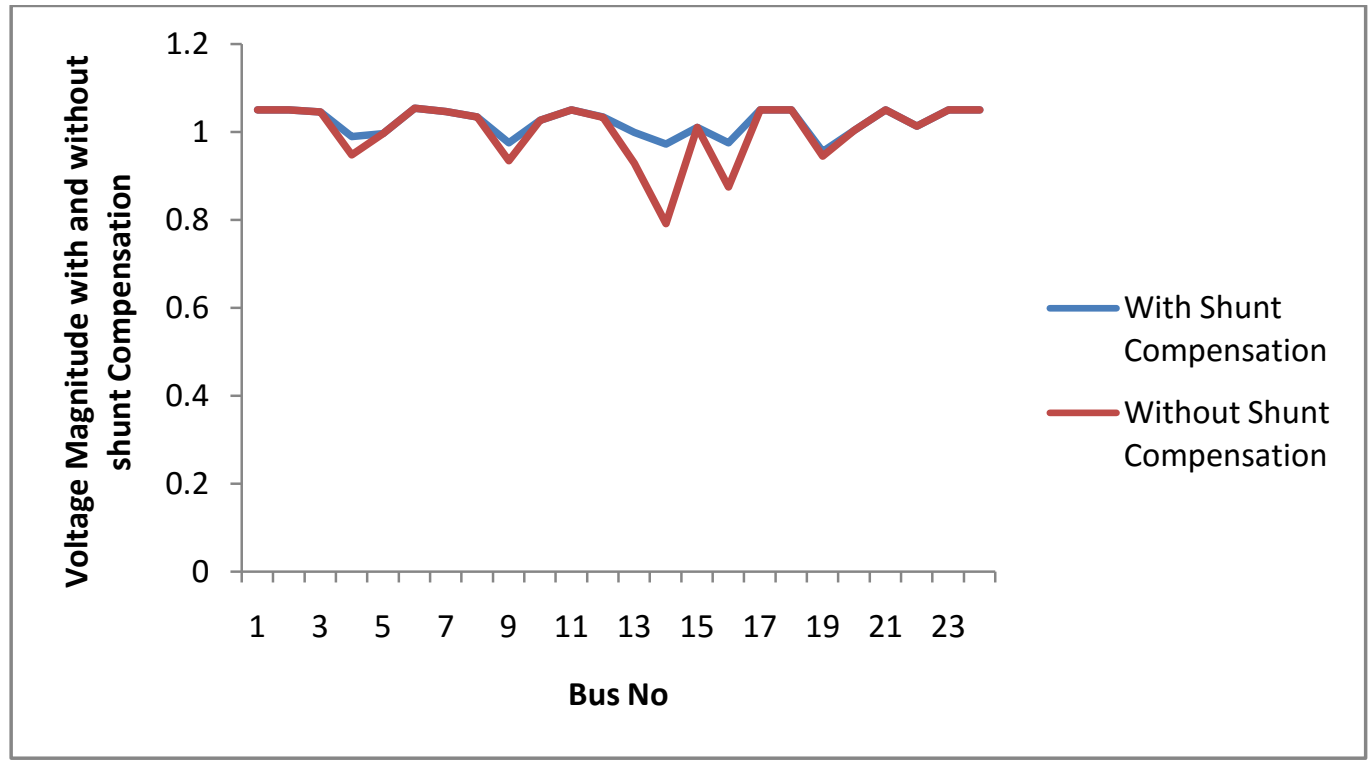

Figure 7: Voltage Magnitude (with and without compensation) versus BusNo

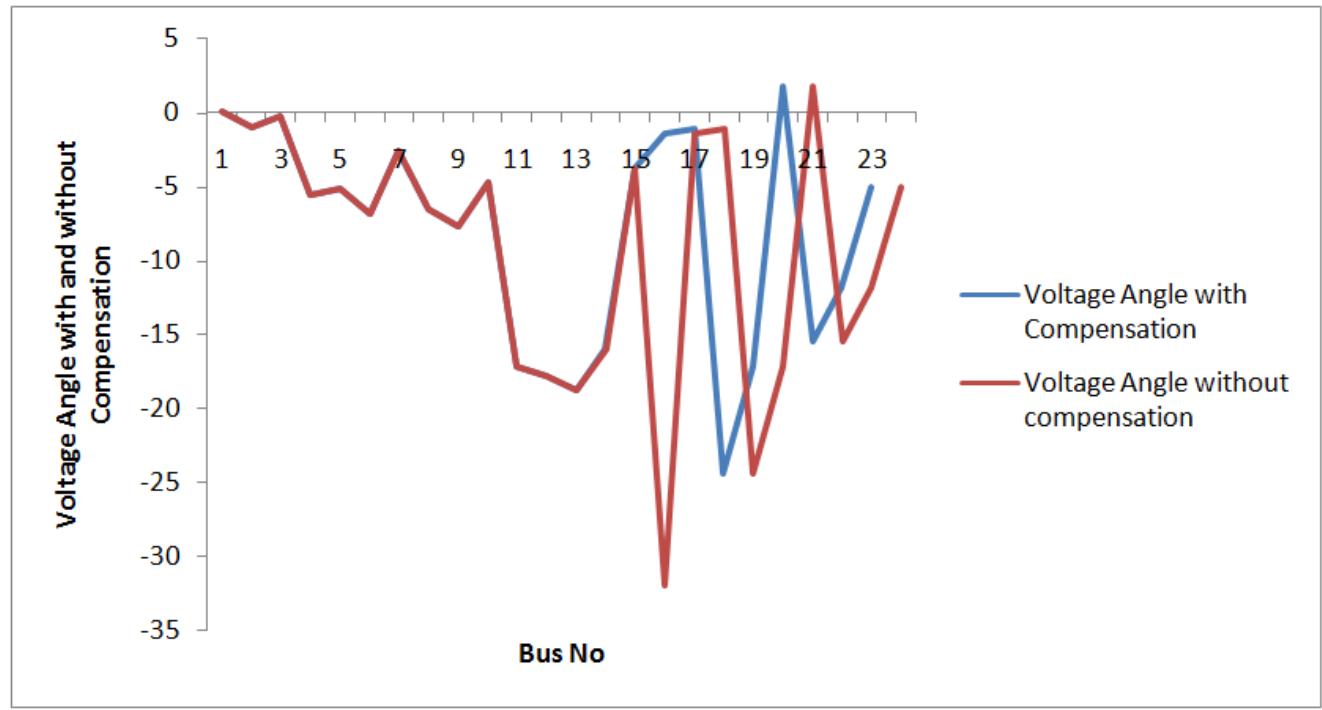

Figure 8: Voltage Angle (with and without compensation) versus Bus No

\section{Conclusion}

Optimal allocation and sizing of reactive power source for voltage profile improvement using power flow program implemented in MATLAB (R2013a version) environment has been presented. The Nigerian $330 \mathrm{kV}$, 24-bus grid system was used as the case study. Newton-Raphson algorithm was used to carry out the power flow analysis with and without shunt compensation, buses with voltage magnitude less than 0.95 p.u were identified, a calculated amount of reactive power injected to raise the voltage within acceptable limit of 0.95 1.05 p.u.

The study shows that the injected MVAr via shunt-type capacitors significantly improve the system voltage profile, voltage angles and the total system losses at steady state condition was found to be 82.5982MW, with shunt compensation the total system losses reduced drastically to 82.2826MW.

\section{References}

[1]. Jokojeje R.A, Adejumobi I A, Adebisi O.I and Mufutau W.O (2015): "Reactive power compensation in Nigeria electricity grid using static synchronous compensator (STATCOM)",IOSR Journal of Electrical and Electronics Engineering (IOSR-JEEE), Vol. 10, Issue 2, Pp. 08-20.

[2]. Pyone L. S, Wanna S and Kyaw M. L (2011): "Effects of tap changing transformer and shunt capacitor on voltage stability enhancement of transmission networks", International Journal of Electrical, Computer, Energetic, Electronic and Communication Engineering Vol.5, No.3, Pp.268-271.

[3]. Thukaram D, Parthasarathy K, Khincha H. P, Udupa N and Bansilal A (1998): "Voltage stability improvement: case studies of Indian power network", Electric Power Systems Research, Vol. 44, No. 1, Pp. 35 - 44. 
[4]. Tamura Y (1993): "Relationship between voltage instability and multiple load flow solutions in electric power systems" IEEE Transaction on Power Systems, Vol. PAS - 102, No.5, Pp.1115-1125.

[5]. Wollenberg B.F (2002): “Transmission system reactive power compensation”, IEEE Power Engineering Society Winter Meeting, Vol.1, Pp. $507-508$.

[6]. Omorogiuwa E and Onohaebi S.O (2015): "Optimal location of IPFC in Nigeria $330 \mathrm{kV}$ integrated power network using GA technique", J Electr Electron System 4: 145. doi:10.4172/2332-0796.1000145, Vol. 4, Issue 1, Pp.1-8.

[7]. Kundur P (1994): "Power system stability and control", McGraw-Hill, New York, USA, Pp.1176-1180.

[8]. Akwukwaegbu I. O and Okwe G. I (2013):"Concepts of reactive power control and voltage stabilitymethods in power system network”, IOSR Journal of Computer Engineering (IOSR-JCE),e-ISSN: 2278-0661, p- ISSN: 2278-8727, Vol.11, Issue 2, Pp. 1525.

[9]. Kundur P, Paserba J and Ajjarapu V (2004): "Power system voltage stability and control”, McGraw-Hill, New York, USA, Pp. $1-7$.

[10]. Tamuraet Y (1993): "Relationship between voltage instability and multiple load flow solutions in electric power systems" IEEE Transaction on Power Systems. Vol.102, No.5,Pp.1115-1125.

[11]. Ademola A, Awosope C.O.A, Samuel I and Agbetuyi A.F (2016): "Contingency Analysis for assessing line loses in Nigeria 330kV Power line”, International Journal of Engineering and Advanced Technology (IJEAT), Vol. 5, Pp.66- 78.

[12]. Iyer S. R, Ramachandran K and Hariharan S (1984): "Optimal reactive power allocation for improved system performance", IEEE Transactions on Power Apparatus and Systems, Vol. PAS-103, Pp.67-75.

[13]. Salamat S, Sharif, James H. T and Eugene F. Hill (1996): "On-line optimal reactive power flow by energy loss minimization", Proceedings of the $35^{\text {th }}$ Conference on Decision and Control, Kobe, Japan. IEEE, Pp. 3851-3856. 